\title{
The reversal of recurrence hazard rate between ER positive and negative breast cancer patients with axillary lymph node dissection (pathological stage I-III) 3 years after surgery
}

\author{
Takayoshi Kiba1,2, Takashi Inamoto*3, Tsutomu Nishimura4 ${ }^{4}$ Masaya Ueno ${ }^{1}$, \\ Kazuhiro Yanagihara ${ }^{1}$, Satoshi Teramukai ${ }^{2,4}$, Hironori Kato ${ }^{5}$, Masakazu Toi ${ }^{5}$ \\ and Masanori Fukushima ${ }^{1,2,4}$
}

\begin{abstract}
Address: ${ }^{1}$ Outpatient Oncology Unit, Kyoto University Hospital, Kyoto, Japan, ${ }^{2}$ Translational Research Informatics Center, Kobe, Japan, ${ }^{3}$ Department of Breast Surgery, Kitano Hospital, The Tazuke Kofukai Medical Research Institute, Osaka, Japan, ${ }^{4}$ Translational Research Center Kyoto University Hospital, Kyoto, Japan and ${ }^{5}$ Department of Breast Surgery, Graduate School of Medicine, Kyoto University, Kyoto, Japan

Email: Takayoshi Kiba - kiba@tri-kobe.org; Takashi Inamoto* - t-inamoto@kitano-hp.or.jp; Tsutomu Nishimura - t246ra@kuhp.kyoto-u.ac.jp; Masaya Ueno - Umasaya@aol.com; Kazuhiro Yanagihara - kazuhiro@kuhp.kyoto-u.ac.jp; Satoshi Teramukai - steramu@kuhp.kyoto-u.ac.jp; Hironori Kato - hkato@kuhp.kyoto-u.ac.jp; Masakazu Toi - toi@kuhp.kyoto-u.ac.jp; Masanori Fukushima - mfukushi@kuhp.kyoto-u.ac.jp

* Corresponding author
\end{abstract}

Published: 7 November 2008

BMC Cancer 2008, 8:323 doi:10.1 186/147|-2407-8-323
Received: 5 March 2008

Accepted: 7 November 2008

This article is available from: http://www.biomedcentral.com/I47I-2407/8/323

(C) 2008 Kiba et al; licensee BioMed Central Ltd.

This is an Open Access article distributed under the terms of the Creative Commons Attribution License (http://creativecommons.org/licenses/by/2.0), which permits unrestricted use, distribution, and reproduction in any medium, provided the original work is properly cited.

\begin{abstract}
Backgrounds: Prognostic factors are defined as biological or clinical measurement associated with overall survival and/or disease-free survival. Previous studies have shown that patients with estrogen receptor (ER) positive cancers have a better prognosis than patients whose cancers do not have these receptors.
\end{abstract}

Methods: This study investigated the assessment of variables in defining prognosis of 742 breast cancer women with pathological stage (PTNM) I-III diagnosed between 1980 and 2005 at the Kyoto University Hospital in Japan, by age, clinical stage (cTNM), PTNM, the numbers of positive lymph nodes ( $\mathrm{pN}$ ), and ER status.

Results: Multivariate analysis demonstrated that PTNM and ER status were the independent prognostic factors for overall survival, and that PTNM and $\mathrm{pN}$ were the independent prognostic factors for disease-free survival. For the 0 - to 2-year interval, the hazard of recurrence was higher for the ER-negative patients than the ER-positive patients, and beyond 3 years the hazard was higher for ER-positive patients.

Conclusion: The present study confirmed the previous reports which showed favorable prognosis of the patients with lesser PTNM or positive ER status. A reversal of recurrence hazard rate between ER positive and negative breast cancer patients beyond 3 years after operation was detected. The fact may indicate the importance of long term adjuvant hormone therapy for ER positive cancer patients. 


\section{Background}

A prognostic factor is defined as a biological or clinical measurement that is associated with overall survival and/ or disease-free survival [1]. The knowledge of prognosis forms an integral part of the decision-making process in medicine [2]. Moreover, prognostic factors are important in the treatment of cancer to help identify subgroups of patients who may need more aggressive approach to therapy [3]. Further, prognostic factors also play a critical role in designing clinical trial as stratification and allocation factors [4]. Prognostic factors, i.e., those that predict the risk of recurrence or death from breast cancer, include stage, number of positive axillary nodes, tumor size, lymphatic and vascular invasion, the estrogen-receptor (ER) and progesterone-receptor (PR) positivity, and HER2/neu gene amplification $[3,5]$. We previously reported that the recent advance of the survival rates in breast cancer patients may be due to the rational development of treatment [6]. In order to assess the independent value of variables in defining prognosis, in the present study, we have investigated the survival of 742 breast cancer patients with pathological stage (pTNM) I-III, by the age, clinical stage (cTNM), pTNM, the numbers of positive lymph nodes $(\mathrm{pN})$ and ER status.

\section{Methods \\ Patients}

742 female beast cancer patients aged between 21 and 80 with stage I-III of pTNM were selected from the patients treated at Kyoto University Hospital in Japan from 1980 to 2005. Based on the section 2 in chapter 1 of Japanese ethical guidelines for epidemiological research http:www.niph.go.jp/english2/english ver/ethical-gl/ guide lines.htm, this study was exempt from ethical approval under Japanese law and guidelines. Moreover, all treatments for breast cancer were undertaken with informed consent and consents were also taken to confirm cancer diagnosis. These patients underwent surgery with axillary lymph node dissection. The operation methods were classified into three groups: breast conserving surgery, modified radical mastectomy, and standard radical mastectomy. All the patients with breast conserving surgery received radiation therapy. Staging of CTNM and pTNM was evaluated according to UICC stage [7]. Number of lymph node metastasis and ER status of the primary tumors were analyzed by staff members of the Department of Pathology at Kyoto University Hospital. Using immunohistochemistry on the whole series of tumors, they assessed estrogen receptor (ER) status in a standardized way. In our institute, the pathologists routinelyhave examined the ER status of tumors by using the immunohistochemistry since the 1980s. The contents of treatments for breast cancer patients were previously described [6]. According to the years of surgery the patients were grouped into two cohorts: period I (1980-
1989) and period II (1990-2005). In period I, modified radical mastectomy with lymph node dissection was included. In this period, breast-conserving surgery was not performed, because it was not recognized to be the prevailing method in Japan. In period II, breast-conserving surgery was the treatment of choice for women with relatively small breast cancers during this past decade in Japan. In our institute, all patients with breast-conversing surgery received radiation therapy. In the treatment stage I, II, IIIA, and operable stage IIIC breast cancer, breastconserving surgery or modified radical mastectomy with lymph node dissection and with or without breast reconstruction surgery was included. In the treatment of stage IIIB and inoperable stage IIIC breast cancer, systemic chemotherapy, or systemic chemotherapy followed by surgery, with lymph node dissection followed by radiation therapy were included. If necessary, additional systemic therapy such as chemotherapy, hormone therapy, or both were given. Moreover, if necessary, adjuvant therapy such as systemic chemotherapy (per os only) with or without hormone therapy (tamoxifen or tremifene) was included. The patients received adjuvant chemotherapy with LH-RH agonist after 2001, cyclophosphamide, epirubicin and 5-fluorouracil (CEF) or Cyclophosphamide, methotrexate and 5-fluouracil (CMF) regimen after 2002, and rational developers such as taxane, trastuzumab, or aromatase inhibitor therapy after 2004.

\section{Statistical analysis}

Disease-free survival was defined from the operation day to the identification date of recurrence of cancer or death from any cause, and overall survival was defined from the operation day to death from any cause. Survival curves were estimated with the Kaplan-Meier method. To identify prognostic factors independently associated with the overall survival or disease-free survival and to estimate the hazard ratios, the Cox proportional hazard model was applied. Two-sided $p<0.05$ was regarded as statistically significant. The statistical analysis was conducted with SPSS version 11.0 statistical software.

\section{Results \\ Patient Characteristics}

Patient characteristics are summarized in Table 1. The medianfollow-uptime of the investigated period in this study was as same as the median follow-up time forsurvivingpatients ( 5.7 years).

\section{0-year overall survival}

The 10-year overall survival rates classified by age, cTNM, pTNM, pN, ER status and types of breast surgery are shown in Table 2. Figure 1 shows the overall survival curves in ER-positive and ER-negative patients. 
Table I: Patient characteristics $(n=742)$

\begin{tabular}{lrr}
\hline & number & $\%$ \\
\hline Gender & & \\
female & 742 & 100 \\
$\quad$ male & 0 & 0 \\
Age & & \\
$\quad<35(2 \mathrm{I}-34)$ & 35 & 4.7 \\
35-54 & 337 & 45.4 \\
$\geq 55$ (55-9I) & 370 & 49.9 \\
cTNM stage & & \\
Stage I & 197 & 26.6 \\
Stage II & 452 & 60.9 \\
Stage III & 93 & 12.5 \\
PTNM stage & & \\
Stage I & 189 & 25.5 \\
Stage II & 397 & 53.5 \\
Stage III & 156 & 21.0 \\
PN & & \\
PN0 & 422 & 56.9 \\
PNI & 189 & 25.5 \\
PN2 & 88 & 11.9 \\
PN3 & 43 & 5.8 \\
ER status & & \\
negative & 290 & 39.1 \\
Positive & 452 & 60.9 \\
Breast surgery & & \\
Breast conserving surgery & 305 & 41.1 \\
Modified radical mastectomy & 429 & 57.8 \\
Standard radical mastectomy & 1.1 \\
\hline
\end{tabular}

\section{0-year disease-free survival}

The 10-year disease-free survival rates classified by age, CTNM, pTNM, pN, ER status and types of breast surgery are shown in Table 3. The approximate 10-year diseasefree survival between ER positive and negative patients was reversed (Figure 2). According to age, cTNM, pTNM and $\mathrm{pN}$, the reversal of disease-free survival was not detected in the present study (Table 3 ).

\section{Estrogen receptor status}

Because beyond 10 years hazard had increased statistical errors, we investigated the annual hazard of recurrence until 10 years after operation. For the 0 - to 2 -year interval, the hazard of recurrence was higher for the ER-negative patients than the ER-positive patients, and beyond 3 years the hazard was higher for ER-positive patients (Figure 3). Figure 4 shows that the overall survival of ER-positive cancer patients was increased by adjuvant hormone therapy ( $p=0.009)$. Moreover, among 452 ER-positive cases, at 1 year after surgery, the hazard of recurrence was higher for the patients with adjuvant hormone therapy than the patients without adjuvant hormone therapy, but between 2 and 4 years, the hazard was higher for the patients without adjuvant hormone therapy (Figure 5).

\section{Prognostic factor analysis}

Age $(<35 ; 35-54 ; \geq 55)$, cTNM (stage I-III), pTNM (stage I-III), pN (pN0, pN1, pN2, pN3), ER status (negative, positive, unknown), and types of breast surgery (breast conserving surgery, modified radical mastectomy, radical mastectomy) were analyzed as potential prognostic factors by the Cox proportional hazard model. Both univariate analyses to determine prognostic factors associated with overall survival and disease-free survival that the features with $p<0.05$ were 5 features: cTNM, pTNM, pN, ER status, and type of surgery (Table 2 \&3). The important prognostic factor associated with overall survival determined by multivariate analyses with backward variables selection were 2 features: pTNM and ER status (Table 4). The important prognostic factor associated with diseasefree survival determined by multivariate analyses with backward variables selection were two features: pTNM and pN (Table 4).

\section{Discussion}

Tumor staging systems provide information about extent of disease that can be used to guide treatment recommendations and provide estimates of patient prognosis. It is well known that pathological stage is the most significant independent prognostic factor for determining survival in breast cancer [8]. Our study documents the fact that pathological stage is the independent prognostic factor for both overall survival and disease-free survival.

Many studies have shown that women with ER positive cancers have a better prognosis than patients whose cancers do not have this receptor $[9,10]$. In this study cohort, ER status were the independent prognostic factors for overall survival by the multivariate Cox regression analysis, but ER status did not affect disease-free survival (Table $3 \& 4)$. Nomura et al. [11] previously reported that in a retrospective multicenter study to investigate the ER status in primary breast cancer with patient prognosis, 3,118 patients with operable breast cancer (stages I-III) were investigated from ten hospitals in Japan who underwent surgery from October 1972 to December 1982, and that Cox's multivariate analysis showed that overall survival, but not disease-free survival was affected by ER status. They speculated the possibility that this was due to the longer postrelapse survival in patients with ER-positive cancer based on the effectiveness of endocrine treatment. Preceding paper has reported that the patients of positive ER status enjoyed benefits from the recent development of breast cancer treatments [6]. In fact, the present study showed that the overall survival of ER-positive cancer patients was increased by adjuvant hormone therapy (Figure 4).

Hortobagyi et al. [12] previously reported that the diseasefree survival in estrogen receptor (ER) positive and/or pro- 
Table 2: The 10-year overall survival rates and univariate Cox regression analysis

\begin{tabular}{|c|c|c|c|c|c|}
\hline \multirow[t]{2}{*}{ Factors } & \multicolumn{2}{|c|}{ overall survival rates } & \multirow[t]{2}{*}{ Hazard ratio } & \multirow[b]{2}{*}{$95 \% \mathrm{Cl}$ a } & \multirow{2}{*}{$\begin{array}{c}\text { Log-rank test } \\
p \text {-value }\end{array}$} \\
\hline & 10-year (\%) & $95 \% \mathrm{Cla}^{\mathrm{a}}$ & & & \\
\hline \multicolumn{6}{|l|}{ Age } \\
\hline$<35$ & 69.6 & $57.7-81.5$ & 1.00 & - & 0.30 \\
\hline $35-54$ & 78.1 & $75.2-81.0$ & 0.69 & $0.30-1.59$ & \\
\hline$\geq 55$ & 73.4 & $69.9-77.0$ & 0.90 & $0.39-2.08$ & \\
\hline \multicolumn{6}{|l|}{ cTNM } \\
\hline Stage I & 85.7 & $81.3-90.0$ & 1.00 & - & $<0.001$ \\
\hline Stage II & 75.8 & $73.1-78.5$ & 2.32 & $1.31-4.09$ & \\
\hline Stage III & 54.5 & $46.9-62.0$ & 4.85 & $2.55-9.22$ & \\
\hline \multicolumn{6}{|l|}{ PTNM } \\
\hline Stage I & 89.4 & $85.8-93.1$ & 1.00 & - & $<0.001$ \\
\hline Stage II & 81.7 & $79.1-84.4$ & 2.10 & $1.10-4.03$ & \\
\hline Stage III & 46.4 & $40.8-51.9$ & 7.77 & $4.08-|4.8|$ & \\
\hline \multicolumn{6}{|l|}{$\mathrm{pN}$} \\
\hline pNO & 86.7 & $84.2-89.1$ & 1.00 & - & $<0.001$ \\
\hline $\mathrm{pNI}$ & 76.4 & $72.1-80.7$ & 1.74 & $1.08-2.82$ & \\
\hline pN2 & 46.6 & $39.7-53.4$ & 5.25 & $3.34-8.27$ & \\
\hline $\mathrm{pN} 3$ & 38.2 & $26.9-49.5$ & 5.34 & $3.01-9.47$ & \\
\hline \multicolumn{6}{|l|}{ ER status } \\
\hline Negative & 71.0 & $67.7-74.3$ & 1.00 & - & 0.012 \\
\hline Positive & 79.5 & $76.5-82.5$ & 0.63 & $0.44-0.91$ & \\
\hline \multicolumn{6}{|l|}{ Breast surgery } \\
\hline Breast conserving surgery & 76.1 & $71.2-81.0$ & 1.00 & - & 0.093 \\
\hline Modified radical mastectomy & 76.2 & 73.7-78.7 & 1.31 & $0.84-2.04$ & \\
\hline Standard radical mastectomy & 19.1 & $2.29-35.8$ & 4.09 & $1.57-10.64$ & \\
\hline
\end{tabular}

a $\mathrm{Cl}$ : Confidence interval.

gesterone receptor $(\mathrm{PgR})$ positive patients was higher than that in ER/PgR negative patients until 5 years after administration of the state-of-the-art adjuvant therapy, however, the disease-free survivals between these groups was

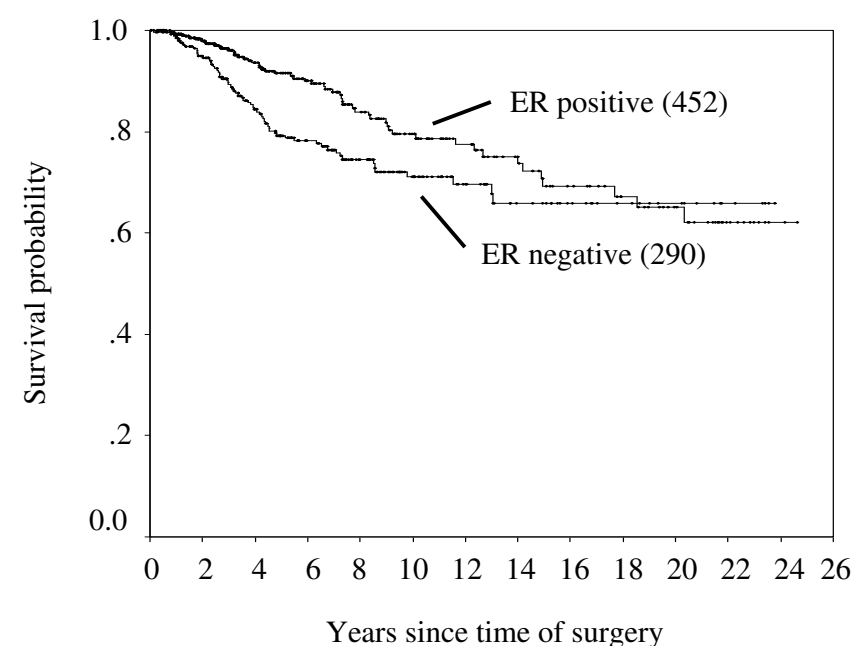

Figure I

Overall survival curves in ER-positive and ER-negative patients. (Number) $=$ number of patients. $p=0.012$. reversed after 5 years. Saphner et al. [13] reported that compared with ER negative patients, ER positive patients had lower annual hazard of recurrence until around 3.5 years after surgery, but thereafter higher. In the present study, Figure 3 shows that a positive ER status was associated with a lower hazard of recurrence in the first 2 years after surgery, but a higher hazard of recurrence from years 3 to 10. [14]. Results from the EBCTCG meta-analysis of systemic treatment of early breast cancer by hormone, cytotoxic, or biologic therapy methods in randomized trials involving 144,939 women show a highly significant advantage of 5 years versus 1 to 2 years of tamoxifen with respect to the risk of recurrence [14]. In the present study, in ER-positive cases, between 2 and 4 years after surgery, the hazard of recurrence of patients without adjuvant hormone therapy was higher than the patients with adjuvant hormone therapy (Figure 5). It is noteworthy that this observation emphasizes the importance of adjuvant hormone therapy for ER positive cancer patients beyond 3 years after operation. Moreover, comparing with the 10year survival rate between ER-positive patients with or without hormone therapy and ER-negative patients (Figure 1 \&4), the survival rate between ER-positive patients without hormone therapy and ER-negative patients was similar, but the adjuvant hormone therapy led about $13 \%$ 
Table 3: The 10-year disease-free survival rates and univariate Cox regression analysis

\begin{tabular}{|c|c|c|c|c|c|}
\hline \multirow[t]{2}{*}{ Factors } & \multicolumn{2}{|c|}{ disease-free survival rates } & \multirow[t]{2}{*}{ Hazard ratio } & \multirow[b]{2}{*}{$95 \% \mathrm{Cl}$ a } & \multirow{2}{*}{$\begin{array}{l}\text { Log-rank test } \\
p \text {-value }\end{array}$} \\
\hline & 10-year (\%) & $95 \% \mathrm{Cl}$ a & & & \\
\hline \multicolumn{6}{|l|}{ Age } \\
\hline$<35$ & 47.0 & $33.3-60.7$ & 1.00 & - & 0.49 \\
\hline $35-54$ & 59.0 & $55.7-62.4$ & 0.91 & $0.50-1.64$ & \\
\hline$\geq 55$ & 63.1 & $59.4-66.7$ & 0.90 & $0.50-1.63$ & \\
\hline \multicolumn{6}{|l|}{ cTNM } \\
\hline Stage I & 72.4 & $67.3-77.6$ & 1.00 & - & $<0.001$ \\
\hline Stage II & 60.9 & $58.0-63.9$ & 2.05 & $1.45-2.91$ & \\
\hline Stage III & 31.5 & $24.8-38.2$ & 5.03 & $3.36-7.52$ & \\
\hline \multicolumn{6}{|l|}{ PTNM } \\
\hline Stage I & 81.7 & $77.4-85.9$ & 1.00 & - & $<0.001$ \\
\hline Stage II & 67.5 & $64.4-70.5$ & 2.18 & $1.47-3.24$ & \\
\hline Stage III & 17.7 & $|3|-22.4$. & 7.66 & $5.13-11.43$ & \\
\hline \multicolumn{6}{|l|}{$\mathrm{pN}$} \\
\hline $\mathrm{pNO}$ & 76.6 & $73.8-79.5$ & 1.00 & - & $<0.001$ \\
\hline $\mathrm{pNI}$ & 56.4 & $51.6-61.2$ & 1.85 & $1.36-2.53$ & \\
\hline pN2 & 15.5 & $10.3-20.7$ & 5.75 & $4.22-7.83$ & \\
\hline $\mathrm{pN} 3$ & 26.8 & $16.6-37.1$ & 4.88 & $3.25-7.32$ & \\
\hline \multicolumn{6}{|l|}{ ER status } \\
\hline Negative & 59.8 & $56.4-63.2$ & 1.00 & - & 0.183 \\
\hline Positive & 60.0 & $56.6-63.4$ & 0.83 & $0.63-1.09$ & \\
\hline \multicolumn{6}{|l|}{ Breast surgery } \\
\hline Breast conserving surgery & 59.1 & $54.1-64.0$ & 1.00 & - & 0.007 \\
\hline Modified radical mastectomy & 61.5 & $58.7-64.3$ & 1.14 & $0.86-1.52$ & \\
\hline Standard radical mastectomy & $\mathrm{ND}^{\mathrm{b}}$ & - & 3.34 & $1.76-6.33$ & \\
\hline
\end{tabular}

a Cl: Confidence interval,b ND: not determined.

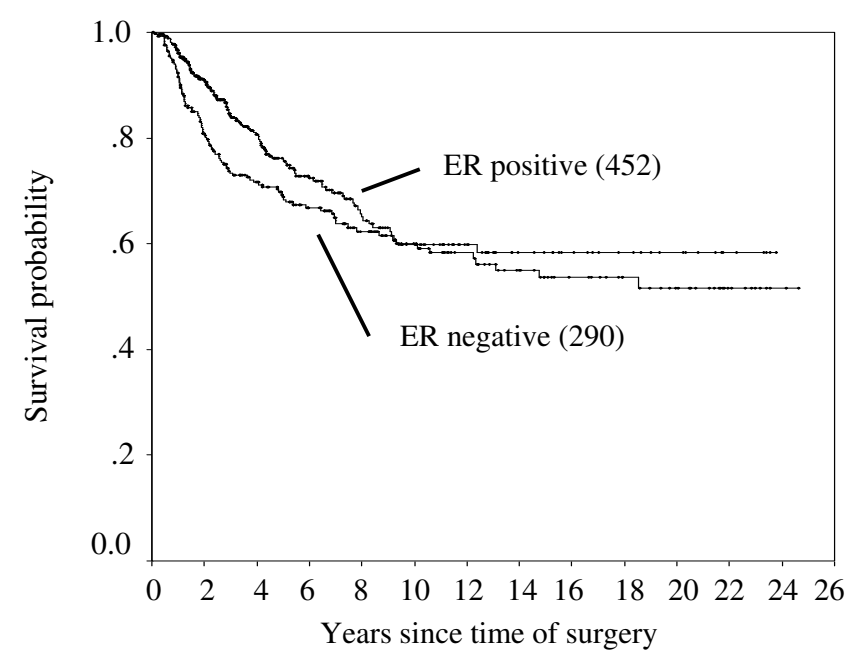

Figure 2

Disease-free survival curves in ER-positive and ERnegative patients. (Number) $=$ number of patients. $p=$ 0.18 .

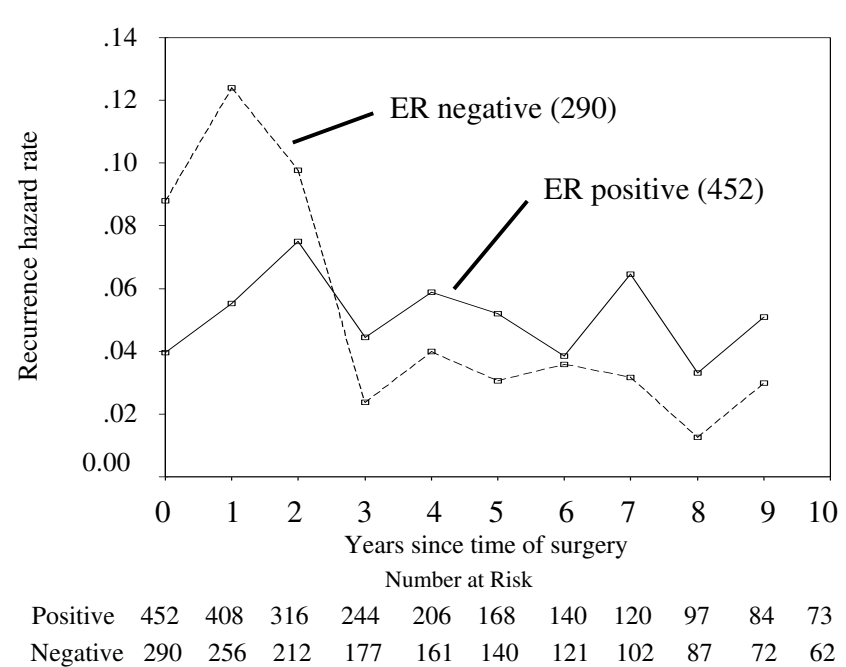

Figure 3

Annual hazard of recurrence of patients separated by ERstatus. (Number) = number of patients. 


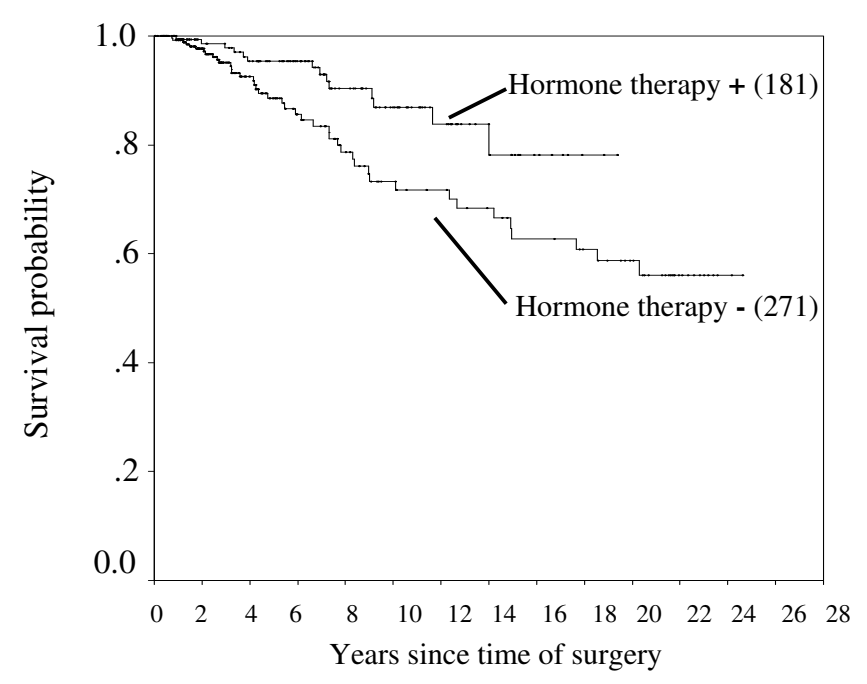

Figure 4

Overall survival curves in ER-positive patients with and without adjuvant hormone therapy. (Number) $=$ number of patients. $p=0.009$.

survival gains. Therefore, this fact also suggests adjuvant hormone therapy may have more important roles in the treatment. In addition, the disease-free survival at 10 years after surgery between ER positive and negative patients was reversed (Figure 2). This may be related to the fact that the percentage of number of patients who received adjuvant hormone therapy in ER positive patients between 1980 and 1991 (11/84: 13\%) was smaller to that between 1991 and 2005 (170/368: 46\%), because of reasons including poor understanding of modern treatment for adjuvant chemotherapy, the cost for drugs, and so on. On

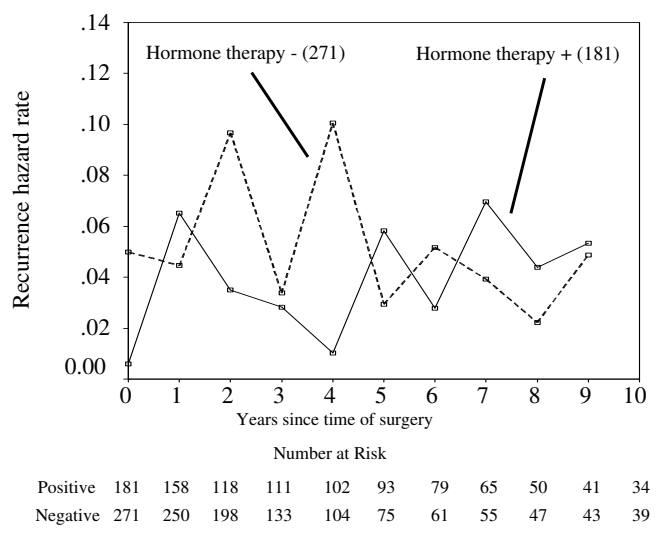

Figure 5

Annual hazard of recurrence of ER-positive patients separated by adjuvant hormone therapy. (Number) $=$ number of patients.
Table 4: Multivariate Cox regression analysis for overall survival and disease-free survival.

\begin{tabular}{|c|c|c|c|}
\hline \multirow[t]{2}{*}{ Factors } & \multicolumn{3}{|c|}{ Overall survival } \\
\hline & Hazard ratio & $95 \% \mathrm{Cl}$ a & $p$-value \\
\hline \multicolumn{4}{|l|}{ PTNM } \\
\hline Stage I & 1.00 & - & \\
\hline Stage II & 2.05 & $1.07-3.94$ & 0.03 \\
\hline Stage III & 8.09 & $4.24-15.43$ & $<0.001$ \\
\hline \multicolumn{4}{|l|}{ ER status } \\
\hline Negative & 1.00 & - & \\
\hline Positive & 0.57 & $0.40-0.82$ & 0.002 \\
\hline \multirow[t]{2}{*}{ Factors } & \multicolumn{3}{|c|}{ Disease-free survival } \\
\hline & Hazard ratio & $95 \% \mathrm{Cl}$ a & $p$-value \\
\hline \multicolumn{4}{|l|}{ pTNM } \\
\hline Stage I & 1.00 & - & \\
\hline Stage II & 1.87 & $1.12-3.11$ & 0.017 \\
\hline Stage III & 3.72 & $1.59-8.70$ & 0.002 \\
\hline \multicolumn{4}{|l|}{$\mathrm{pN}$} \\
\hline pNO & 1.00 & & \\
\hline $\mathrm{pNI}$ & 1.49 & $1.01-2.20$ & 0.044 \\
\hline pN2 & 2.47 & $1.14-5.34$ & 0.022 \\
\hline pN3 & 1.91 & $0.83-4.39$ & 0.129 \\
\hline
\end{tabular}

a Cl: Confidence interval

the other hand, the current recommendation is that adjuvant tamoxifen be discontinued after 5 years in all patients as current standard therapy, because there was a trend toward a worse outcome associated with a longer duration of treatment [15]. Further analyses may be needed to clarify the optimal duration of adjuvant hormone therapy in operated breast cancer patients.

Traditional prognostic factors, i.e., those that predict the risk of recurrence or death from breast cancer, include number of positive axillary nodes [3]. It has been reported that the $\mathrm{pN}$ is the most important prognostic factor affecting disease-free survival and overall survival in operable breast cancer patients [2]. However, our study suggested that $\mathrm{pN}$ is the independent prognostic factor for diseasefree survival, but not for overall survival. The patients with axillary lymph node metastasis have received chemotherapy, hormonal therapy or both. Over the past 20 years, various systemic adjuvant therapies have been studied to improve survival [6]. Therefore, there may be a possibility that the other factors such as these therapies may affect the overall survival more stronger than $\mathrm{pN}$, although further investigations are needed to clarify this matter.

The univariate Cox regression analysis for overall survival and disease-free survival demonstrated that the hazard ratio of patients with breast conserving surgery was lower 
than that of patients with standard radical mastectomy (Table 2 \&3). This fact suggests that breast conserving surgery with radiation therapy may provide not only cosmetic benefit but also better prognosis, although chronological change of breast cancer treatments may affect the survival rates.

In conclusion, the present study presented the data of the long term survival of pathological stage I-III patients with breast cancers at our institution. For the 0- to 2-year interval, the hazard of recurrence was higher for the ER-negative patients than the ER-positive patients, and beyond 3 years the hazard was higher for ER-positive patients. Additionally, disease free survival 10 years after operation was reversed between ER-positive and negative patients. Therefore, the fact may indicate the importance of long term adjuvant hormone therapy for ER positive cancer patients.

\section{Abbreviations}

CTNM: clinical stage; ER: estrogen receptor; pTNM: pathological stage; $\mathrm{pN}$ : positive lymph nodes.

\section{Competing interests}

The authors declare that they have no competing interests.

\section{Authors' contributions}

TI and MF designed this study. MU, KY, HK, TI collected and assembled the data. TI organized the data. TK, TN, ST, TI and MF contributed to the statistical analyses and interpretations. TK, TI, MT and MF contributed to writing and finalizing of the manuscript. All authors read and approved the final manuscript.

\section{Acknowledgements}

The authors received no specific funding for this study.

\section{References}

I. DeVita VT, Hellman S, Rosenberg SA: Cancer: Principles and Practice of Oncology Philadelphia: Lippincott Williams \& Wilkins; 2001.

2. Gospodarowicz M, Mackillop W, O'Sullivan B, Sobin L, Henson D, Hutter RV, Wittekind C: Prognostic factors in clinical decision making: the future. Cancer 200I, 9 I (8 Suppl): I688- 1695.

3. Clark GM: Do we really need prognostic factors for breast cancer? Breast Cancer Res Treat 1994, 30(2): I 17-I26.

4. Hedden S, Woolson R, Malcolm R: Randomization in substance abuse clinical trials. Substance Abuse Treatment, Prevention, and Policy 2006, I(6): I- I7.

5. Goldhirsch A, Wood WC, Gelber RD, Coates AS, Thürlimann B, Senn HJ: 10th St. Gallen conference. Progress and promise: highlights of the international expert consensus on the primary therapy of early breast cancer 2007. Ann Oncol 2007, 18(7): I |33-I| 44.

6. Ueno M, Kiba T, Nishimura T, Kitano T, Yanagihara K, Yoshikawa K, Ishiguro $\mathrm{H}$, Teramukai S, Fukushima M, Kato H, Inamoto T: Changes in survival during the past two decades for breast cancer at the Kyoto University Hospital. Eur J Surg Oncol 2007, 33(6):696-699.

7. Sobin LH, Wittekind CH: TNM Classification of malignant Tumors New York: Wiley-Liss; 2002.
8. Pritchard KI: Prognostic and Predictive Factors for Breast Cancer. Proceedings of 26th Annual San Antonio Breast Cancer Symposium; December 3 - 6, 2003, San Antonio .

9. Pritchard KI: The best use of adjuvant endocrine treatments. Breast 2003, I 2(6):497-508.

10. Pritchard KI: Adjuvant endocrine therapies for pre-/perimenopausal women. Breast 2005, I 4(6):547-554.

II. Nomura Y, Miura S, Koyama H, Enomoto K, Kasumi F, Yamamoto H, Kimura M, Tominaga $T$, lino $H$, Morimoto $T$, et al.: Relative effect of steroid hormone receptors on the prognosis of patients with operable breast cancer. A univariate and multivariate analysis of 3089 Japanese patients with breast cancer from the Study Group for the Japanese Breast Cancer Society on Hormone Receptors and Prognosis in Breast Cancer. Cancer 1992, 69(I):153-164.

12. Hortobagyi GN, Kau SW, Buzdar AU, Theriault RL, Booser DJ, Gwyn $\mathrm{K}$, Valero $\mathrm{V}$ : What is the prognosis of patients with operable breast cancer five years after diagnosis? Proc Am Soc Clin Oncol 1994, 23:585A.

13. Saphner T, Tormey DC, Gray R: Annual hazard rates of recurrence for breast cancer after primary therapy. J Clin Oncol 1996, I 1(10):2738-2746.

14. Early Breast Cancer Trialists' Collaborative Group (EBCTCG): Effects of chemotherapy and hormonal therapy for early breast cancer on recurrence and 15-year survival: an overview of the randomised trials. Lancet 2005, 365(9472): 1687-1717.

15. Swain SM: Tamoxifen: the long and short of it. J Natl Cancer Inst 1996, 88(2I): $1510-1512$.

\section{Pre-publication history}

The pre-publication history for this paper can be accessed here:

\section{http://www.biomedcentral.com/1471-2407/8/323/pre} pub

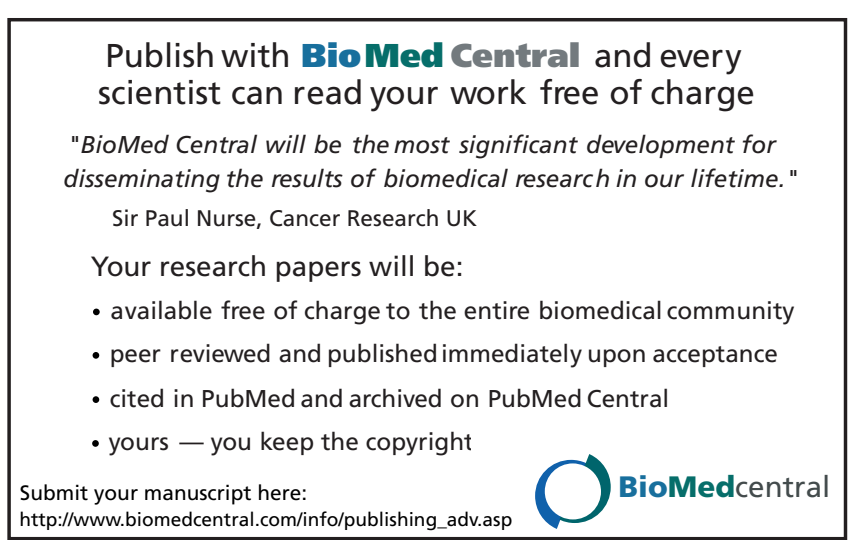

